\title{
Article \\ Modification of Magnetite Nanoparticles with Triazine-Based Dendrons and Their Application as Drug-Transporting Systems
}

\author{
Mateusz Pawlaczyk* (D) and Grzegorz Schroeder (D) \\ Faculty of Chemistry, Adam Mickiewicz University in Poznań, Uniwersytetu Poznańskiego 8, \\ 61-614 Poznań, Poland; schroede@amu.edu.pl \\ * Correspondence: mateusz.pawlaczyk@amu.edu.pl; Tel.: +48-618291797
}

Citation: Pawlaczyk, M.; Schroeder,

G. Modification of Magnetite

Nanoparticles with Triazine-Based Dendrons and Their Application as Drug-Transporting Systems. Int. J. Mol. Sci. 2021, 22, 11353. https:// doi.org/10.3390/ijms222111353

Academic Editor: Jyh-Ping Chen

Received: 31 August 2021

Accepted: 19 October 2021

Published: 21 October 2021

Publisher's Note: MDPI stays neutral with regard to jurisdictional claims in published maps and institutional affiliations.

Copyright: () 2021 by the authors. Licensee MDPI, Basel, Switzerland. This article is an open access article distributed under the terms and conditions of the Creative Commons Attribution (CC BY) license (https:// creativecommons.org/licenses/by/ $4.0 /)$.

\begin{abstract}
The following research aims at the synthesis of magnetite nanoparticles functionalized with triazine-based dendrons and the application of the obtained materials as effective sorptive materials dedicated to acidic bioactive compounds. The adopted synthetic approach involved: (1) the synthesis of nanosized $\mathrm{Fe}_{3} \mathrm{O}_{4}$ particles via classic co-precipitation method, (2) the introduction of amine groups on their surface leading to materials' precursor, and (3) the final synthesis of branched triazinebased dendrons on the support surface by an iterative reaction between cyanuric chloride (CC) and piperazine (p) or diethylenetriamine (DETA) via nucleophilic substitution. The characterized materials were tested for their adsorptive properties towards folic acid, $18 \beta$-glycyrrhetinic acid, and vancomycin, showing high adsorption capacities varying in the ranges of 53.33-401.61, 75.82-223.71, and $68.17-132.45 \mathrm{mg} \mathrm{g}^{-1}$, respectively. The formed material-drug complexes were also characterized for the drug-delivery potential, performed as in vitro release studies at $\mathrm{pH} 2.0$ and 7.4 , which mimics the physiological conditions. The release profiles showed that the proposed materials are able to deliver up to $95.2 \%$ of the drugs within $48 \mathrm{~h}$, which makes them efficient candidates for further biomedical applications.
\end{abstract}

Keywords: triazine-based dendrons; magnetite nanoparticles; magnetic hybrid materials; in vitro drug delivery; adsorption

\section{Introduction}

Recently, hybrid materials based on oxide nanoparticles [1,2], especially magnetite (iron(II,III) oxide; $\mathrm{Fe}_{3} \mathrm{O}_{4}$ ) nanoparticles, gained significant attention as starting materials for the synthesis of tools dedicated to chemical analysis, adsorbents, supports for the delivery of various biocompounds, or catalysts, owing to their various beneficial physicochemical features. Namely, magnetite nanoparticles might be obtained using a wide range of easily accessible synthetic procedures (co-precipitation, thermal decomposition, hydrothermal method, etc.), which finally exhibit magnetic susceptibility, and thus might be easily separated using an external magnetic field. Moreover, due to the presence of multiple surface hydroxyl groups, magnetite particles are prone to direct surface functionalization or encapsulation within the silica matrix, leading to easily tunable $\mathrm{Fe}_{3} \mathrm{O}_{4} / \mathrm{SiO}_{2}$ systems [3-7].

The choice of functionalizing agents is always driven by the targeted applications of the designed materials. Among a plethora of organic domains used for surface functionalization, dendritic structures have gained significant attention due to their multifunctionality and biocompatibility, which influence a wide range of dendrimer-modified hybrid materials' applications [8-10]. The family of dendrimers includes a type of triazine dendrimers, which contain triazine rings interconnected by a polynucleophilic agent, especially linear diamines or aminoalcohols. Characteristic features of triazine-based dendrimers are easiness in tunability afforded by chlorine atoms in the triazine-core undergoing nucleophilic substitution under mild conditions, the rigidity of the final structure afforded by the stiffness of triazine aromatic ring, and a combination of both hydrophobic and hydrophilic 
domains in the macromolecule. This kind of dendrimers was introduced to chemical nomenclature in the early 2000s [11] and was studied for the improvement of pharmacokinetic parameters of chosen drugs, with the simultaneous possibility of enhancing their therapeutic effects [12-16], delivering nucleic acids to cancer cells [17], as well as promising binding efficiency towards toxic metal ions [18,19].

Hence, the process of immobilization of triazine-based dendrimers on the inorganic support surface may lead to obtaining hybrid materials that have versatile applications since the dendritic receptors may form coordinating, electrostatic, $\pi-\pi$ stacking, or inclusive interactions with analytes. Therefore, several materials containing surface triazine dendrimers or triazine-based dendrons have been investigated for the chelation of toxic metal ions, including $\mathrm{Pb}(\mathrm{II}), \mathrm{Cu}(\mathrm{II})$, or $\mathrm{Hg}(\mathrm{II})$ ions, as well as toxic organic compounds, such as dyes or phenol derivatives [20-24]. The metal binding properties also triggered the application of such materials as metal-containing catalysts dedicated to various organic reactions, affording excellent conversion rates and chemo- or stereoselectivity [25-29]. Surprisingly, hitherto literature presents only a few reports concerning the bioapplication of the materials functionalized with triazine-dendrimers. Nevertheless, magnetite nanoparticles conjugated with methotrexate through triazine dendrimers or dopamine-triazine linkers were investigated for enhanced drug delivery to various cell cultures [30,31].

In the context of the applicability of triazine-based dendrimers and dendrons in drug delivery and the insufficiency in current research studies, the following article concerns the synthesis of magnetite nanoparticles functionalized with triazine-dendrons and their further application as sorptive materials towards chosen bioactive compounds, which were folic acid, $18 \beta$-glycyrrhetinic acid, and vancomycin. The studies should address the characterization of the designed materials and investigate the influence of the structure of anchored triazine-based dendrons on the materials' adsorptive properties, as well as their ability to transport the chosen drugs based on the drug release to aqueous media.

\section{Results and Discussion}

\subsection{Synthesis and Characterization of Triazine Dendron-Functionalized Magnetite Nanoparticles}

The nanoparticles of magnetite were synthesized following the standard co-precipitation approach, while their further encapsulation with a thin silica layer was performed via the Stöber process [32]. The prepared $\mathrm{Fe}_{3} \mathrm{O}_{4} / \mathrm{SiO}_{2}$ particles were then subjected to functionalization with a silane derivative containing aminopropyl chain, leading to a magnetically susceptible material with free terminal $\mathrm{NH}_{2}$ groups as a precursor for the synthesis of the designed triazine dendron-grafted materials. Obtaining the final hybrid materials was based on two steps: (a) the incorporation of cyanuric chloride (CC) - a branching unit - to terminal amine groups and (b) the introduction of the aminocomponent (diethylenetriamine (DETA); or piperazine (p)). The aforementioned synthetic approach is illustrated in Figure 1. Each of the steps is based on the substitution of chlorine atoms of cyanuric chloride with amine groups, either anchored to the surface or added as a reactant. The main advantage of the adopted method is the chemoselectivity of chlorine atoms undergoing nucleophilic substitution at different reaction conditions. Namely, the substitution of the first chlorine atom takes place at a lowered temperature of $<2{ }^{\circ} \mathrm{C}$, the second atom at room temperature, and the third at elevated temperature (reflux); thus, the temperature control allows for easy directing of the dendrons growth. Therefore, following the described synthetic protocol, two materials containing first-generation dendrons, G1 (only one branching level; materials $\mathrm{Fe}_{3} \mathrm{O}_{4}-\mathrm{CC}-\mathrm{p}$ and $\mathrm{Fe}_{3} \mathrm{O}_{4}-\mathrm{CC}-\mathrm{DETA}$ ), and two materials containing second-generation dendrons, $\mathrm{G} 2$ (two branching levels; materials $\mathrm{Fe}_{3} \mathrm{O}_{4}-(\mathrm{CC}-\mathrm{p})_{2}$ and $\left.\mathrm{Fe}_{3} \mathrm{O}_{4}-(\mathrm{CC}-\mathrm{DETA})_{2}\right)$, were obtained, which are presented in Figure 2. 


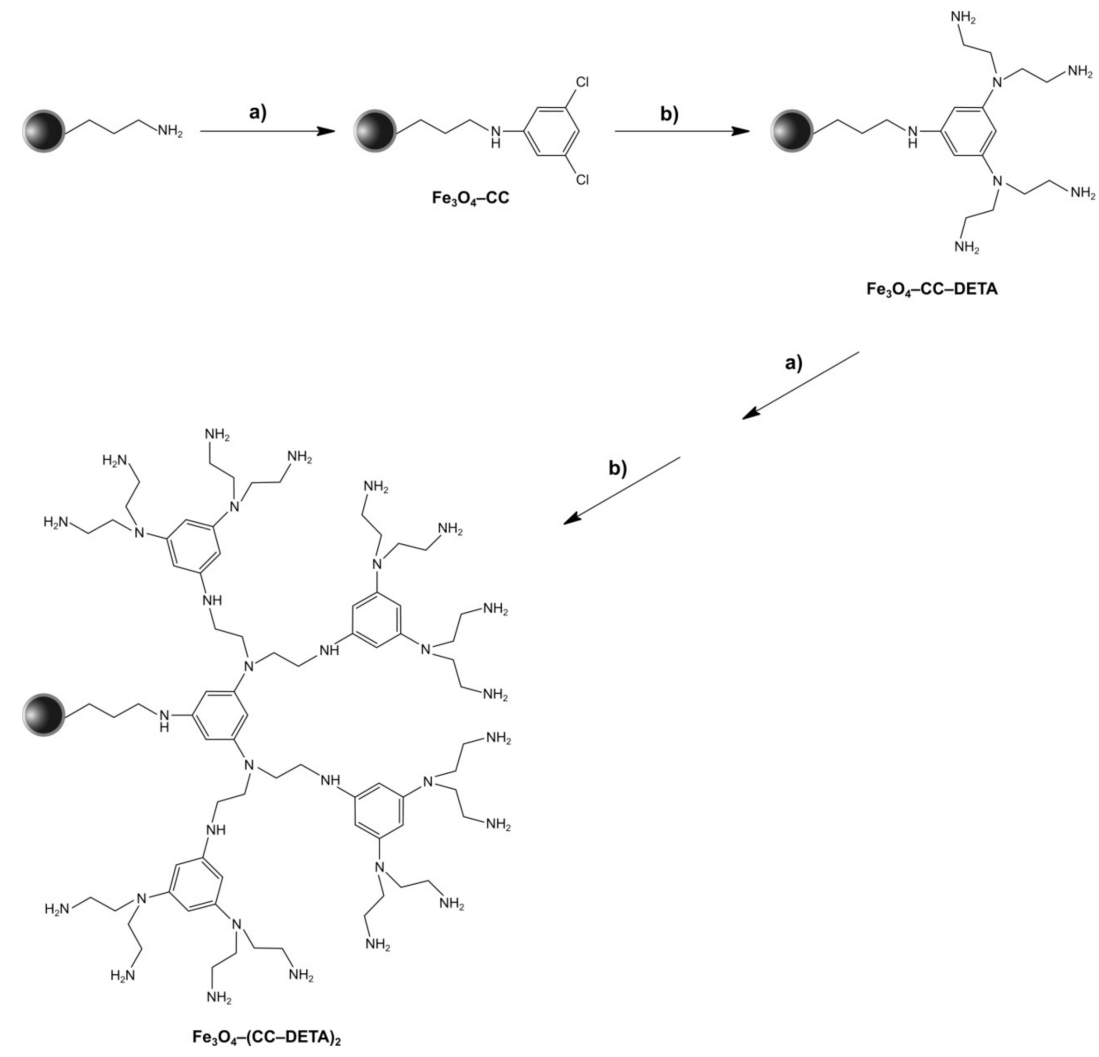

Figure 1. The synthetic protocol for obtaining the triazine dendron-functionalized magnetite nanoparticles as an introduction of cyanuric chloride (CC) and diethylenetriamine (DETA) to the surface of $\mathrm{Fe}_{3} \mathrm{O}_{4}-\mathrm{NH}_{2}$ : (a) CC, THF, $2{ }^{\circ} \mathrm{C}-2 \mathrm{~h}$; (b) DETA, ACN, RT-16 h, reflux-24 h.

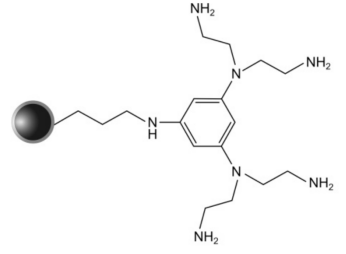

$\mathrm{Fe}_{3} \mathrm{O}_{4}-\mathrm{CC}-\mathrm{DETA}$

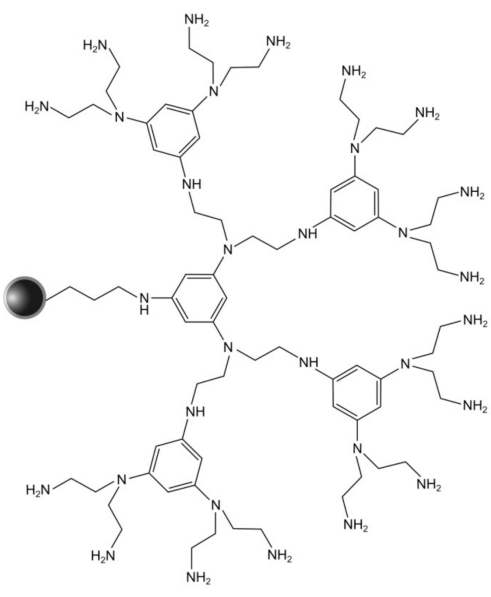

$\mathrm{Fe}_{3} \mathrm{O}_{4}$-(CC-DETA $)_{2}$

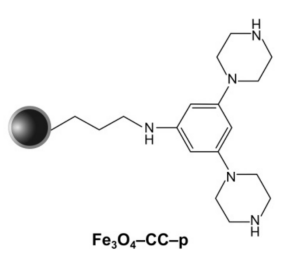

$\mathrm{e}_{3} \mathrm{O}_{4}-\mathrm{CC}-\mathrm{p}$

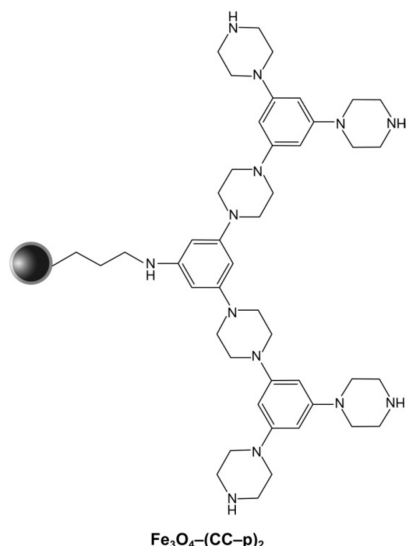

$\mathrm{Fe}_{3} \mathrm{O}_{4}-(\mathrm{CC}-\mathrm{p})_{2}$

Figure 2. The structures of the obtained the triazine dendrons-modified magnetic nanoparticles. 
All the synthesized materials and their intermediates were characterized with FT-IR analysis, and the spectra are presented in Figure 3. Each spectrum exhibits several bands, common for all the materials, including a very strong absorption band of $\mathrm{Fe}-\mathrm{O}$ lattice stretching centered approximately at $590 \mathrm{~cm}^{-1}$, a broad band with a maximum at around $1050 \mathrm{~cm}^{-1}$ assigned for the stretching vibrations of Si-O-Si domains, a relatively low intense signal of $-\mathrm{CH}_{2}-$ stretching at around $2925 \mathrm{~cm}^{-1}$, or a very broad band between 3100 and $3500 \mathrm{~cm}^{-1}$ with a maximum at around $3410 \mathrm{~cm}^{-1}$, corresponding to either the stretching of free hydroxyl groups on $\mathrm{Fe}_{3} \mathrm{O}_{4} / \mathrm{SiO}_{2}$ surface or/and the stretching of $\mathrm{N}-\mathrm{H}$ domains. Additionally, after the first step of incorporation of cyanuric chloride to the nanomaterial's surface, new, common for all the functionalized materials, signals at 798, 894 , and broad signal 1600 and $1660 \mathrm{~cm}^{-1}$ appeared, referring to the vibrations of the trisubstituted aromatic ring of triazine. Moreover, with the growth of triazine-based dendrons on the materials' surface, several signals between 1300 and $1500 \mathrm{~cm}^{-1}$, corresponding to various $\mathrm{C}-\mathrm{N}$ stretching, or $\mathrm{C}-\mathrm{H}$ and $\mathrm{N}-\mathrm{H}$ bending, became more intensive, which proved the successful grafting the reagents on the materials. Interestingly, the steps of cyanuric chloride incorporation were undoubtedly proved by the appearance of signals at around 843 and $1238 \mathrm{~cm}^{-1}$, which are related to the vibrations of $\mathrm{C}-\mathrm{Cl}$.
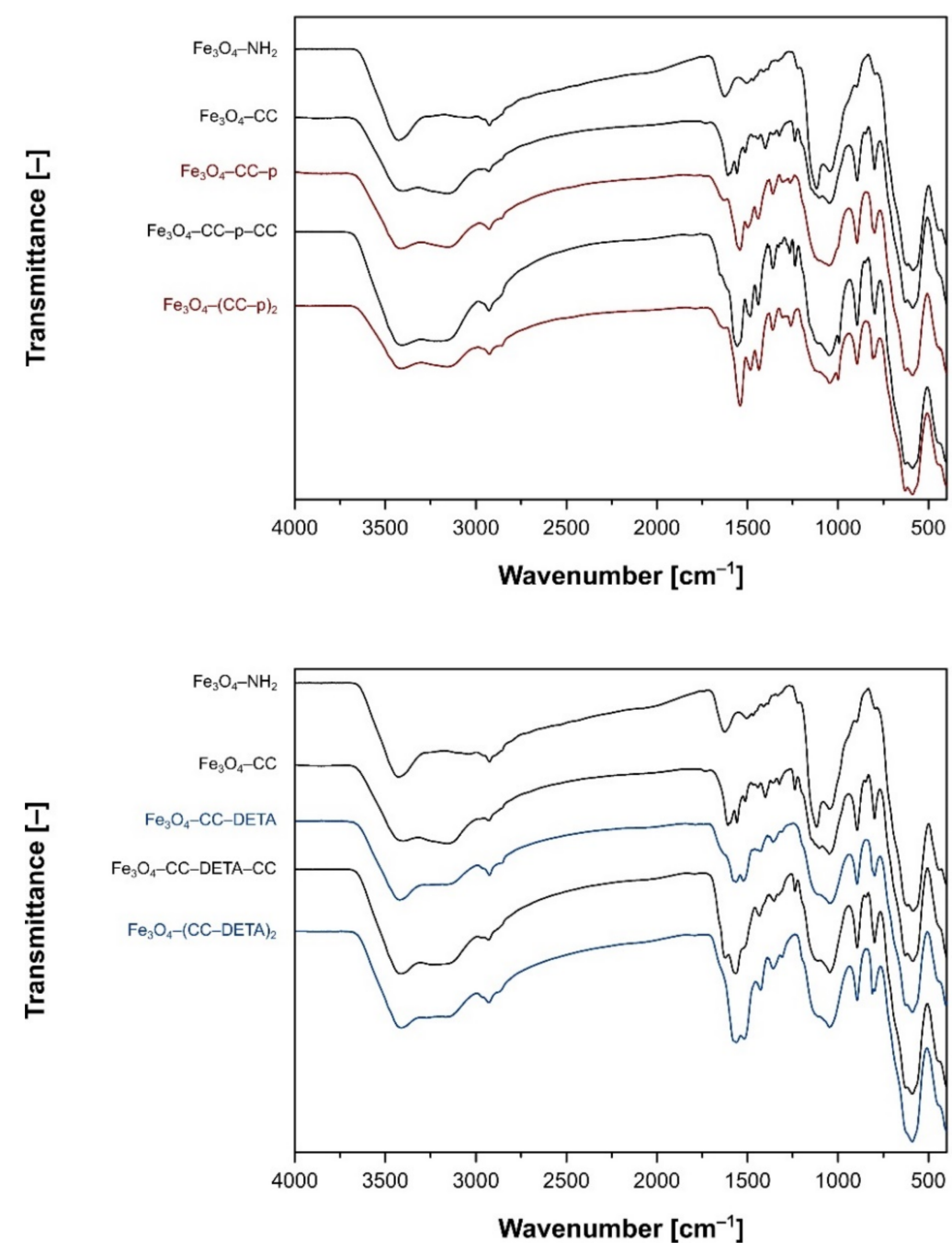

Figure 3. The FT-IR spectra of the magnetic support $\left(\mathrm{Fe}_{3} \mathrm{O}_{4}-\mathrm{NH}_{2}\right)$, the cyanuric chloride (CC) intermediates $\left(\mathrm{Fe}_{3} \mathrm{O}_{4}-\mathrm{CC}\right.$ and $\mathrm{Fe}_{3} \mathrm{O}_{4}-\mathrm{CC}$-amine-CC), and the dendron-functionalized materials $\left(\mathrm{Fe}_{3} \mathrm{O}_{4}-\mathrm{CC}\right.$-amine and $\left.\mathrm{Fe}_{3} \mathrm{O}_{4}-(\mathrm{CC} \text {-amine })_{2}\right)$ containing piperazine (p) (top) and diethylenetriamine (DETA) (bottom) as an amine domain. 
All the dendron-functionalized materials were tested for the content of the terminal amine groups based on the classic acid-base titration method. The calculated loading of amine groups $L_{a}$ and loading of the dendrons' residues $L_{d}$ are presented in Table 1 . The loading values of amine groups calculated for the materials containing piperazine as the aminocomponent are noticeably lower than the corresponding values for DETAcontaining materials, which is related to the structural features of both amines used. However, the values of quantified dendrons' loading are significantly higher for piperazinebased dendrons than those calculated for DETA-based dendrons. Such results are strictly connected with the various reactivity of structurally different amines for the substitution of chlorine atoms in cyanuric chlorine, which are mainly attributed to steric effects and amine's $\mathrm{pK}_{\mathrm{a}}$ values, and can be presented in the following order: cyclic aliphatic amines $>$ linear aliphatic amines $>$ aryl amines [33]. Therefore, the first and the second incorporation of piperazine domain to the materials $\mathrm{Fe}_{3} \mathrm{O}_{4}-\mathrm{CC}-\mathrm{p}$ and $\mathrm{Fe}_{3} \mathrm{O}_{4}-(\mathrm{CC}-\mathrm{p})_{2}$, respectively, was achieved with a higher yield and with insignificant yield loss during the second substitution step, unlike the incorporation of DETA domains into the corresponding materials.

Table 1. The amine groups loading and the porous properties of the final triazine dendron-functionalized materials.

\begin{tabular}{|c|c|c|c|c|c|}
\hline \multirow{2}{*}{ Material } & \multicolumn{2}{|c|}{$\begin{array}{c}\text { Loading } \\
\left(\mathrm{mmol} \mathrm{g}^{-1}\right)\end{array}$} & \multicolumn{3}{|c|}{$\mathrm{N}_{2}$ Adsorption/Desorption Analysis } \\
\hline & $\mathbf{L}_{\mathbf{a}}$ & $\mathbf{L}_{\mathbf{d}}$ & $\begin{array}{l}\text { Surface Area } \\
\qquad\left(\mathrm{m}^{2} \mathrm{~g}^{-1}\right)\end{array}$ & $\begin{array}{l}\text { Pore Size } \\
\text { (nm) }\end{array}$ & $\begin{array}{l}\text { Pore Volume } \\
\left(\mathrm{cm}^{3} \mathrm{~g}^{-1}\right)\end{array}$ \\
\hline $\mathrm{Fe}_{3} \mathrm{O}_{4}-\mathrm{CC}-\mathrm{p}$ & 0.390 & 0.195 & 68.914 & 30.9 & 0.533 \\
\hline $\mathrm{Fe}_{3} \mathrm{O}_{4}-(\mathrm{CC}-\mathrm{p})_{2}$ & 0.719 & 0.180 & 71.672 & 32.1 & 0.575 \\
\hline $\mathrm{Fe}_{3} \mathrm{O}_{4}-\mathrm{CC}-\mathrm{DETA}$ & 0.467 & 0.117 & 58.259 & 86.0 & 0.542 \\
\hline $\mathrm{Fe}_{3} \mathrm{O}_{4}-(\mathrm{CC}-\mathrm{DETA})_{2}$ & 1.104 & 0.069 & 62.063 & 65.9 & 0.515 \\
\hline
\end{tabular}

Moreover, the materials containing full dendrons of the first or second generation were analyzed for their porous features using the $\mathrm{N}_{2}$ adsorption/desorption method, which isotherms are presented in Figure 4, while the obtained porosity parameters are listed in Table 1. The effect of the dendrons' generation on the porous properties of the materials is rather insignificant, which is proved by a high similarity of the corresponding isotherms obtained for the materials grafted with dendrons of the first and second generation. The pore size values calculated for the materials containing first-generation piperazine-dendrons are lower than those calculated for DETA-dendrons, which is connected with the branching character of both amines. Piperazine as the structurally compact amine creates the smaller cavities, while DETA triggers the creation of bigger pores since its attachment leads to branched units. On the other hand, the second coupling step promotes the formation of a bigger size for $\mathrm{Fe}_{3} \mathrm{O}_{4}-(\mathrm{CC}-\mathrm{p})_{2}$, while smaller for $\mathrm{Fe}_{3} \mathrm{O}_{4}-(\mathrm{CC}-\mathrm{DETA})_{2}$, which is connected with loosing and tightening of the dendrons, respectively. These findings are consistent with pore volume values, also listed in Table 1.

\subsection{Investigation of Adsorptive Properties of the Dendron-Functionalized Magnetic Materials towards Bioactive Compounds}

The synthesized and characterized materials have been studied for their binding potential of three biocompounds: folic acid, 18 $\beta$-glycyrrhetinic acid, and vancomycin, which are presented in Figure 5. The choice of these biologically active agents was predominantly driven by their acidic character (presence of free carboxylic groups), which triggers their attractive interaction through the exchange of a proton between the $-\mathrm{COOH}$ domain of the analytes and free terminal $-\mathrm{NH}-$ or $-\mathrm{NH}_{2}$ groups of the synthesized triazinebased dendrons. Such an exchange leads to a formation of two oppositely charged species undergoing electrostatic interaction, and thus the drugs adsorb on the materials' surface. 

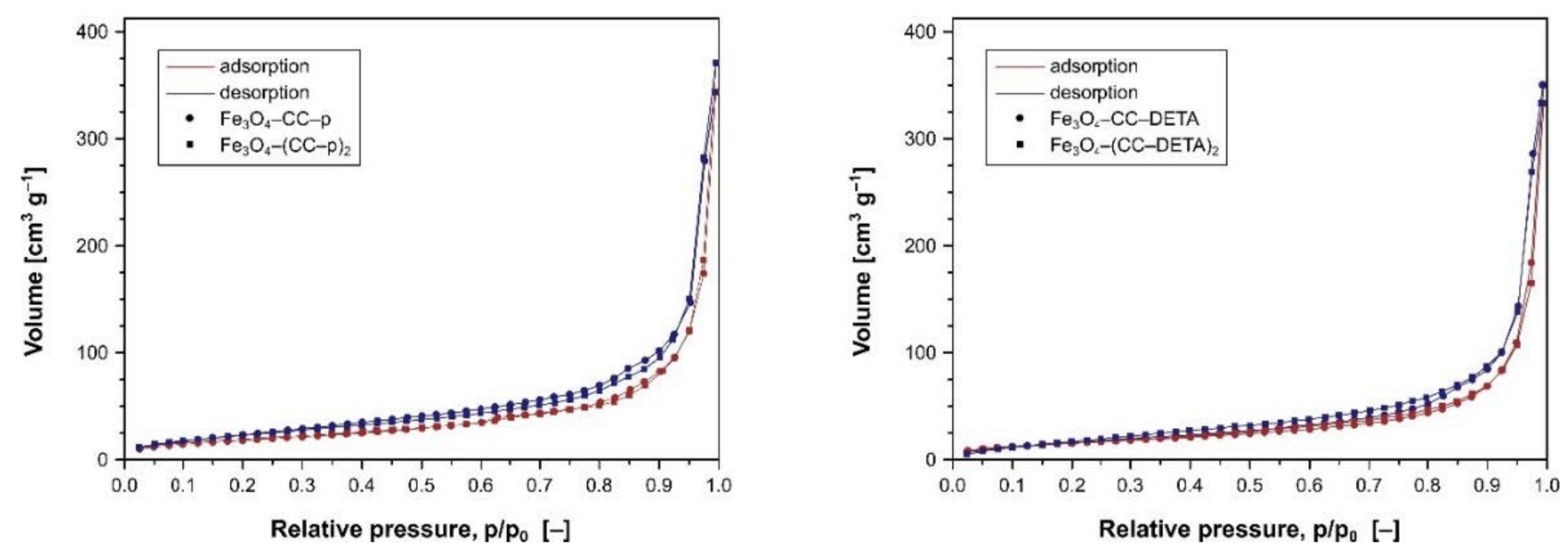

Figure 4. The BET isotherms of the materials containing piperazine-dendrons (left) and DETA-dendrons (right).<smiles>Nc1nc2ncc(CNc3ccc(C(=O)NC(CCC(=O)O)C(=O)O)cc3)nc2c(=O)[nH]1</smiles>

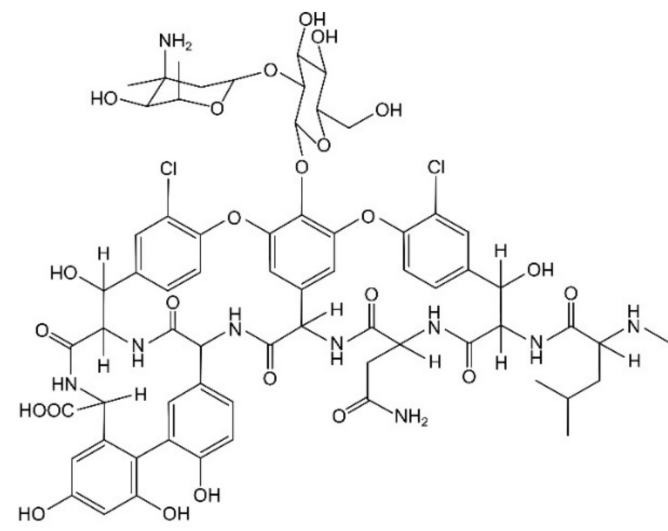

$18 \beta-$ Glycyrrhetinic acid

\section{Vancomycin}

Figure 5. The structures of the biocompounds used in the studies.

All the obtained dendron-modified supports were subjected to adsorption isothermal studies. The experimental data were further fitted to the Langmuir (Supplementary Figure S1) and the Freundlich (Figure 6) models, which parameters are collected in Table 2. Each of the adsorption processes followed the Freundlich isothermal model, proved by significantly higher linear correlation coefficient $\mathrm{R}^{2}$ values than those calculated for the Langmuir model, as well as lower values of $\chi^{2}$, proving better correlation with the regression line. Such results are easily explainable since the Freundlich model assumes the probability of the intermolecular interactions of adsorbate molecules, which potentially happens through the $\pi-\pi$ stacking effect of phenyl rings of the analytes. The calculated $1 / n$ parameters, connected with the strength of the adsorption process, reached very high values $>0.80$, indicating the high adsorptive potential of the materials [34,35]. Nevertheless, on the basis of the experimental data fitting to the Langmuir model, the maximal adsorption capacity values $q_{m}$ were calculated, which are collected in Table 2 . The adsorptive potential of the materials towards the chosen drugs is strictly dependent on both the structure of the pending triazine-based dendrons and the structure of the drugs. The materials containing double-branched dendrons ((CC-p $)_{2}$ and (CC-DETA $)_{2}$ domains) showed two times higher adsorption capacities than the materials containing corresponding singlebranched domains, which is caused by the presence of a higher number of terminal amine groups that are able to interact with the drugs molecules. Additionally, the use of DETA as an aminocomponent has led to the materials of higher sorptive potential than those containing piperazine as a repetitive block, which is due to the (a) better branching character of DETA, leading to more expanded dendritic structures, and (b) the incorporation of a higher number of free $-\mathrm{NH}_{2}$ groups on the materials' surface. Taking the aforementioned 
dependence into account, the least adsorptive material is material $\mathrm{Fe}_{3} \mathrm{O}_{4}-\mathrm{CC}-\mathrm{p}$, in which the adsorption capacities towards the biomolecules varied between 53.33 and $75.82 \mathrm{mg} \mathrm{g}^{-1}$, while the most potent adsorptive material is $\mathrm{Fe}_{3} \mathrm{O}_{4}-(\mathrm{CC}-\mathrm{DETA})_{2}$, in which the sorptive capacity was in the range of $132.42-401.61 \mathrm{mg} \mathrm{g}^{-1}$ for the drugs used. On the other hand, the structure of the adsorbate's molecules also influences their ability to interact with the surface of the materials. Among the three used drugs, folic acid is the only molecule containing two carboxylic molecules, leading to an enhanced stabilization of its electrostatic interactions with amine groups on the materials' surface, which is especially proven for its adsorption on the materials functionalized with DETA-containing dendrons, reaching $q_{m}$ values of 170.07 and $401.61 \mathrm{mg} \mathrm{g}^{-1}$ for $\mathrm{Fe}_{3} \mathrm{O}_{4}-\mathrm{CC}-\mathrm{DETA}$ and $\mathrm{Fe}_{3} \mathrm{O}_{4}-(\mathrm{CC}-\mathrm{DETA})_{2}$, respectively. In the case of vancomycin - a glycosylated polypeptide - the carboxylic group is hindered with a sterically expanded residue, which might decrease its ability to interact with the materials. Nevertheless, the materials showed an adsorption capacity towards vancomycin in the range of $68.17-132.45 \mathrm{mg} \mathrm{g}^{-1}$.

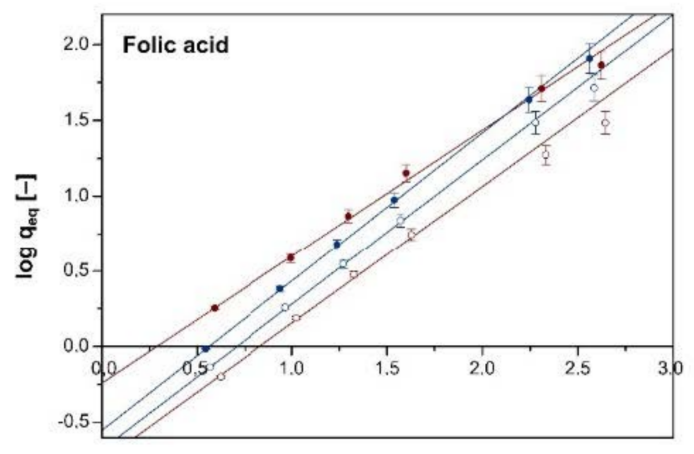

$\log c_{e q}[-]$
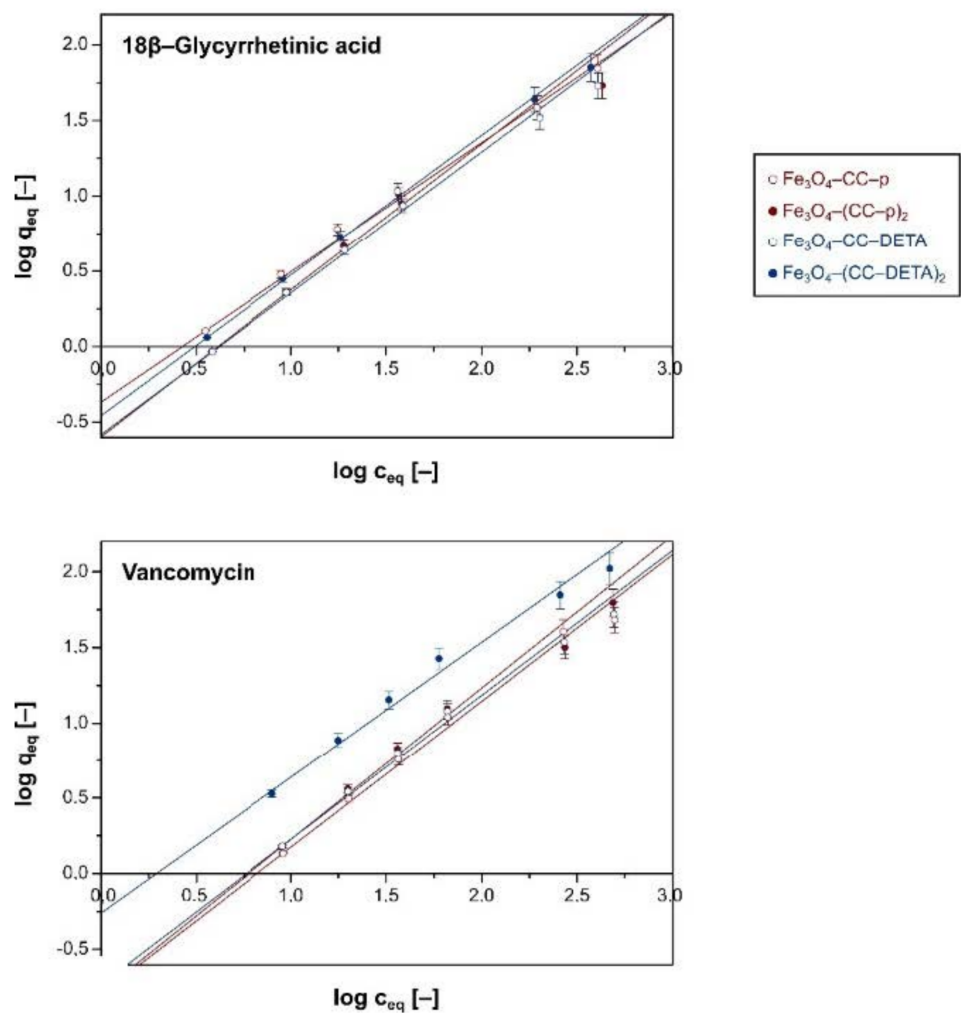

Figure 6. The fitting of the experimental data of the adsorption of the biomolecules on the surface of the dendron-functionalized hybrid materials by the Freundlich model. 
Table 2. The isothermal parameters calculated for experimental data of the drug adsorption on the synthesized materials functionalized with triazine-based dendrons.

\begin{tabular}{|c|c|c|c|c|c|c|}
\hline \multirow{2}{*}{ Material } & \multicolumn{3}{|c|}{ Langmuir Isotherm } & \multicolumn{3}{|c|}{ Freundlich Isotherm } \\
\hline & $\mathrm{q}_{\mathrm{m}}\left(\mathrm{mg} \mathrm{g}^{-1}\right)$ & $\mathbf{R}^{2}$ & $x^{2}$ & $1 / n(-)$ & $\mathbf{R}^{2}$ & $x^{2}$ \\
\hline \multicolumn{7}{|c|}{ Folic Acid } \\
\hline $\mathrm{Fe}_{3} \mathrm{O}_{4}-\mathrm{CC}-\mathrm{p}$ & $53.33 \pm 4.44$ & 0.9794 & 0.072 & $0.91 \pm 0.02$ & 0.9930 & 0.029 \\
\hline $\mathrm{Fe}_{3} \mathrm{O}_{4}-(\mathrm{CC}-\mathrm{p})_{2}$ & $123.92 \pm 9.54$ & 0.9476 & 0.044 & $0.84 \pm 0.03$ & 0.9971 & 0.008 \\
\hline $\mathrm{Fe}_{3} \mathrm{O}_{4}-\mathrm{CC}-\mathrm{DETA}$ & $170.07 \pm 18.32$ & 0.9880 & 0.047 & $0.96 \pm 0.02$ & 0.9991 & 0.005 \\
\hline $\mathrm{Fe}_{3} \mathrm{O}_{4}-(\mathrm{CC}-\mathrm{DETA})_{2}$ & $401.61 \pm 10.56$ & 0.9960 & 0.005 & $0.99 \pm 0.02$ & 0.9995 & 0.003 \\
\hline \multicolumn{7}{|c|}{ 18 $\beta-$ Glycyrrhetinic Acid } \\
\hline $\mathrm{Fe}_{3} \mathrm{O}_{4}-\mathrm{CC}-\mathrm{p}$ & $75.82 \pm 4.90$ & 0.9658 & 0.102 & $0.86 \pm 0.01$ & 0.9902 & 0.034 \\
\hline $\mathrm{Fe}_{3} \mathrm{O}_{4}-(\mathrm{CC}-\mathrm{p})_{2}$ & $176.99 \pm 20.68$ & 0.9801 & 0.009 & $0.97 \pm 0.02$ & 0.9987 & 0.007 \\
\hline $\mathrm{Fe}_{3} \mathrm{O}_{4}-\mathrm{CC}-\mathrm{DETA}$ & $114.16 \pm 11.75$ & 0.9894 & 0.019 & $0.94 \pm 0.02$ & 0.9969 & 0.015 \\
\hline $\mathrm{Fe}_{3} \mathrm{O}_{4}-(\mathrm{CC}-\mathrm{DETA})_{2}$ & $223.71 \pm 21.68$ & 0.9723 & 0.013 & $0.93 \pm 0.02$ & 0.9988 & 0.005 \\
\hline \multicolumn{7}{|c|}{ Vancomycin } \\
\hline $\mathrm{Fe}_{3} \mathrm{O}_{4}-\mathrm{CC}-\mathrm{p}$ & $68.17 \pm 8.38$ & 0.9698 & 0.274 & $0.83 \pm 0.02$ & 0.9932 & 0.022 \\
\hline $\mathrm{Fe}_{3} \mathrm{O}_{4}-(\mathrm{CC}-\mathrm{p})_{2}$ & $97.66 \pm 9.07$ & 0.9747 & 0.149 & $0.86 \pm 0.02$ & 0.9971 & 0.017 \\
\hline $\mathrm{Fe}_{3} \mathrm{O}_{4}-\mathrm{CC}-\mathrm{DETA}$ & $73.10 \pm 6.62$ & 0.9639 & 0.307 & $0.82 \pm 0.02$ & 0.9991 & 0.019 \\
\hline $\mathrm{Fe}_{3} \mathrm{O}_{4}-(\mathrm{CC}-\mathrm{DETA})_{2}$ & $132.45 \pm 6.70$ & 0.9682 & 0.172 & $0.77 \pm 0.03$ & 0.9995 & 0.019 \\
\hline
\end{tabular}

The materials containing the dendrons of the second generation $\left((\mathrm{CC}-\mathrm{p})_{2}\right.$ and $(\mathrm{CC}-$ DETA $)_{2}$ domains) with the adsorbed drugs on their surface were subjected to FAPA-MS analysis, which involves the ionization of the analyte in the flow of plasma generated outside the spectrometer using the Flowing Atmospheric-Pressure Afterglow (FAPA) ionization technique. In the case of the three studied biocompounds, the only one which was ionizable from the material-drug complexes in the plasma stream was $18 \beta$-glycyrrhetinic acid. The FAPA-MS spectra of materials $\mathrm{Fe}_{3} \mathrm{O}_{4}-(\mathrm{CC}-\mathrm{p})_{2}$ and $\mathrm{Fe}_{3} \mathrm{O}_{4}-(\mathrm{CC}-\mathrm{DETA})_{2}$ with adsorbed $18 \beta$-glycyrrhetinic acid are presented in Figure 7 , and the results undoubtedly prove its successful adsorption onto the surface of triazine-based dendron-functionalized materials by the appearance of a signal at $m / z 471.5$ related to the drug's molecular peak. Additionally, the spectrum of $\mathrm{Fe}_{3} \mathrm{O}_{4}-(\mathrm{CC}-\mathrm{DETA})_{2}$ exhibits an additional intensive signal at $m / z$ 425.6, which corresponds to a fragmentation signal of $18 \beta$-glycyrrhetinic acid after a loss of carboxylic group. This signal was observed as the main fragmentation signal in the $\mathrm{MS}^{2}$ spectrum during fragmentation of molecular peak $m / z 471.5$ of $18 \beta$-glycyrrhetinic acid.

\subsection{Investigation of the Materials' Drug-Delivery Potential}

The delivery potential of the materials functionalized with triazine-based dendrons of the second generation (materials $\mathrm{Fe}_{3} \mathrm{O}_{4}-(\mathrm{CC}-\mathrm{p})_{2}$ and $\left.\mathrm{Fe}_{3} \mathrm{O}_{4}-(\mathrm{CC}-\mathrm{DETA})_{2}\right)$ towards the studied three drugs was investigated by the monitoring of the drugs' release from their material-drug complexes in two different aqueous media: $\mathrm{HCl} / \mathrm{KCl}$ buffer of $\mathrm{pH} 2.0$ and phosphate-buffered saline (PBS) of $\mathrm{pH}$ 7.4. The choice of such release media was driven by the conditions, which mimic the conditions of human fluids: gastric juice and human plasma, respectively.

The investigated release profiles (Figure 8) show that in an acidic environment of $\mathrm{pH} 2.0$, a burst release appears within the first $2 \mathrm{~h}$, which is connected with the drastic protonation of drugs' carboxylate domains, hindering the attractive interactions between the materials and the drugs. Such a burst release led to the release of approximately $65-85 \%$ of the drugs in $2 \mathrm{~h}$, with a slight drug release increase within the next 2 days of incubation. On the other hand, the experiments involving the material-drug complexes' incubation in PBS solution of $\mathrm{pH} 7.4$ showed that the progressive release of the biomolecules reached a quasi-plateau after $8 \mathrm{~h}$ for folic acid and vancomycin. In the case of $18 \beta$-glycyrrhetinic acid, its release in $\mathrm{pH} 7.4$ proceeded with a continuous manner within the full time of incubation. Moreover, in each release profile, a similar trend of a slightly higher release percentage from $\mathrm{Fe}_{3} \mathrm{O}_{4}-(\mathrm{CC}-\mathrm{DETA})_{2}$ than $\mathrm{Fe}_{3} \mathrm{O}_{4}-(\mathrm{CC}-\mathrm{p})_{2}$ is observed. It may be caused by 
the more disruptive influence of the adsorbing agents used towards interactions between carboxylate groups of the drugs and protonated $-\mathrm{NH}_{3}{ }^{+}$groups of the terminal DETA domain than those of the $-\mathrm{NH}_{2}{ }^{+}$- groups of piperazine. Furthermore, among all the studied drugs, vancomycin exhibits its highest release percentage from the triazine-based dendron-functionalized materials, varying between $72.5 \%$ and $95.2 \%$, which might be a result of the least intensive interaction between vancomycin and the materials' surface due to the drug's steric hindrance. Nevertheless, the cumulative drug release after $48 \mathrm{~h}$ incubation of folic acid- and 18 $\beta$-glycyrrhetinic acid-loaded materials ranged between $56.4 \%$ and $84.5 \%$ and $58.6 \%$ and $83.4 \%$, respectively, indicating their efficient release to the aqueous media.
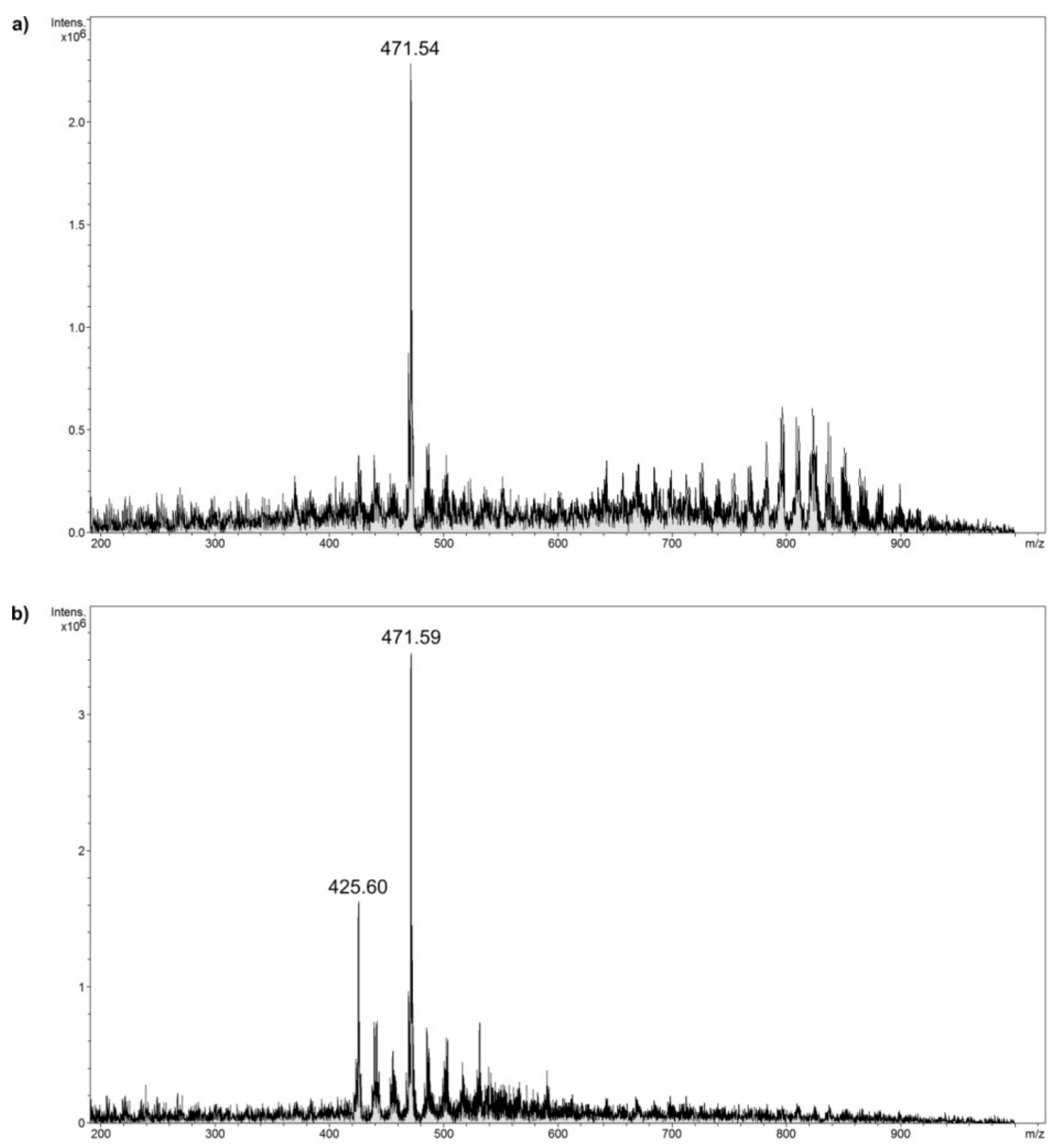

Figure 7. The FAPA-MS spectra of $18 \beta$-glycyrrhetinic acid thermally desorbed from its complexes with: (a) $\mathrm{Fe}_{3} \mathrm{O}_{4}-(\mathrm{CC}-\mathrm{p})_{2}$ and (b) $\mathrm{Fe}_{3} \mathrm{O}_{4}-(\mathrm{CC}-\mathrm{DETA})_{2}$ hybrid materials.

The experimental data of the drug releases from the hybrid materials were also fitted to several drug release kinetic models, which were the zero-order, the first-order, the Higuchi, the Hixson-Crowell, and the Korsmeyer-Peppas models, which linear forms are collected in Table 3. Among all the proposed models, the Korsmeyer-Peppas model showed the best fitting to the investigated release experiments, which is proved by the highest values of $R^{2}$ correlation coefficients (Table 4). Accordingly, it can be postulated that the drugs' release from the hybrid materials follows the Fickian or quasi-Fickian diffusion model, which is connected with the calculated $n$ values significantly lower than 0.45 [36]. The fitting of experimental data to the zero-order, the first-order, and the Hixson-Crowell models gave very low $R^{2}$ values (Supplementary Table $S 1$ ), which indicates that the drugs' releases do not follow these models. 
Release in pH 2.0
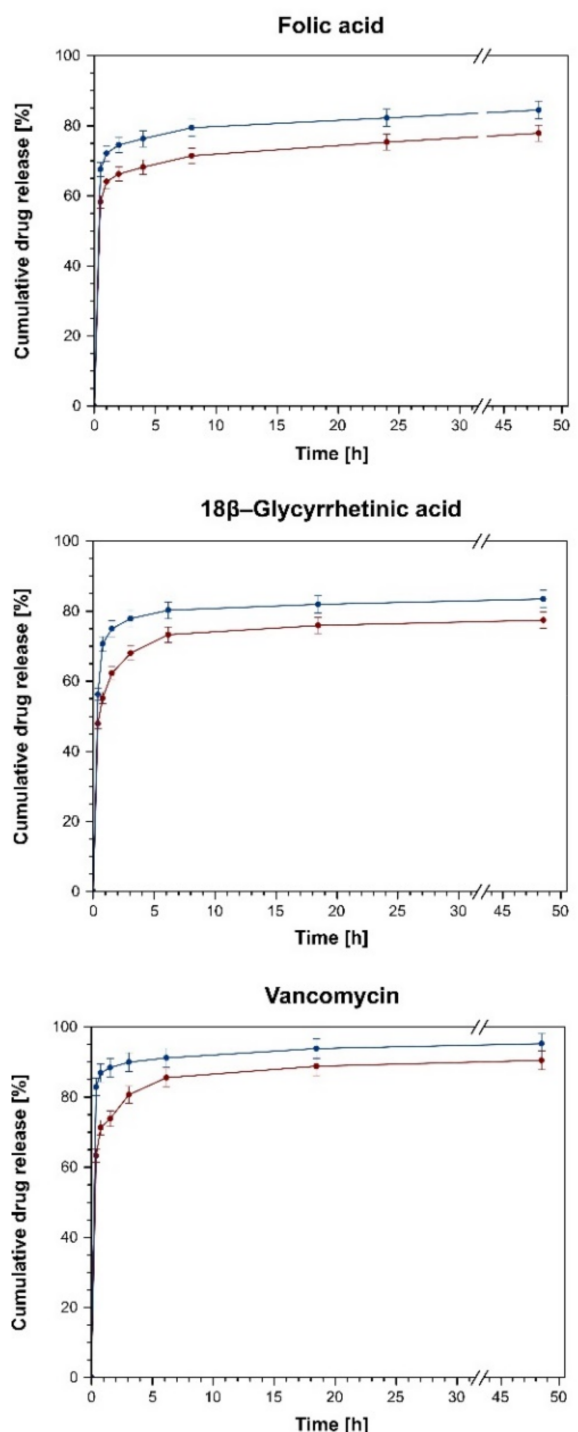

Release in pH 7.4
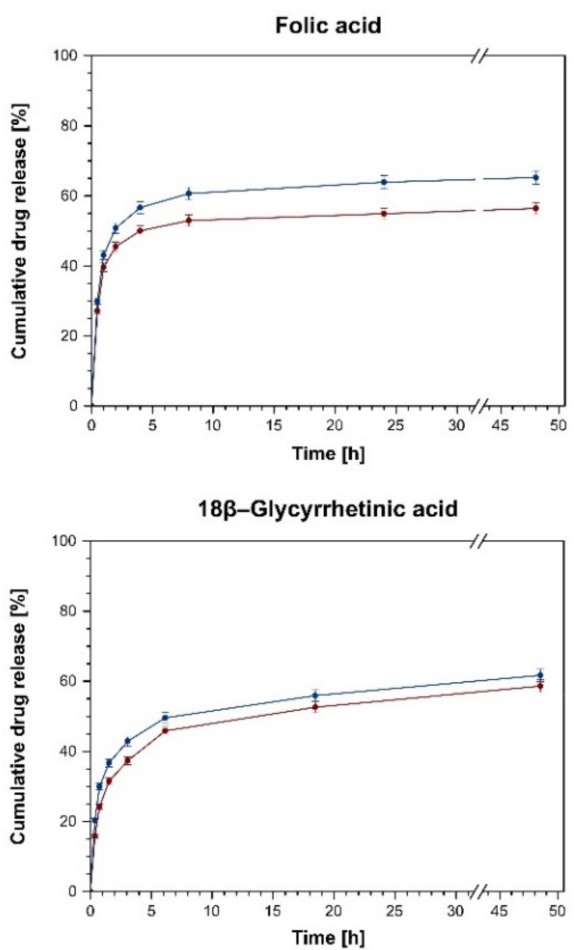

$\mathrm{Fe}_{3} \mathrm{O}_{4}-(\mathrm{CC}-\mathrm{p})_{2}$

- $\mathrm{Fe}_{3} \mathrm{O}_{4}-(\mathrm{CC}-\mathrm{DETA})_{2}$

Figure 8. The profiles of the drugs releases from their complexes with $\mathrm{Fe}_{3} \mathrm{O}_{4}-(\mathrm{CC}-\mathrm{p})_{2}$ (red) and $\mathrm{Fe}_{3} \mathrm{O}_{4}-(\mathrm{CC}-\mathrm{DETA})_{2}$ (blue) performed in two different environments: $\mathrm{pH} 2.0$ (left) and $\mathrm{pH} 7.4$ (right).

Table 3. The description of the drug-release models applied for the fitting of the experimental data.

\begin{tabular}{|c|c|c|}
\hline Drug Release Model & Linear Representation & Parameters \\
\hline Zero-order model & $F_{t}=F_{0}+k_{0} t$ & $\begin{array}{c}F_{0} \text { and } F_{t} \text { - the initial and the cumulative amount of the drug } \\
\text { released at time } t \text {, respectively (mg) }\end{array}$ \\
\hline Hixson-Crowell model & $\sqrt[3]{F_{0}}-\sqrt[3]{F_{t}}=-k_{H-C} t$ & $\begin{array}{l}k_{0} \text { - the zero-order release constant }\left(\mathrm{mg} \mathrm{h}^{-1}\right) \\
k_{H-C} \text { - the Hixson-Crowell release constant }\left(\mathrm{mg}^{1 / 3} \mathrm{~h}^{-1}\right)\end{array}$ \\
\hline First-order model & $\log \left(100-Q_{t}\right)=-k_{1} t$ & $\begin{array}{l}Q_{t} \text { - the cumulative percentage of the drug releases at time } t(\%) \\
k_{1} \text {-the first-order release constant }\left(\% \mathrm{~h}^{-1}\right)\end{array}$ \\
\hline Higuchi model & $Q_{t}=k_{H} \sqrt{t}$ & $\begin{array}{c}k_{H} \text {-the Higuchi release constant }\left(\% \mathrm{~h}^{-1 / 2}\right) \\
n \text {-the Korsmeyer-Peppas exponent of release }(-)\end{array}$ \\
\hline Korsmeyer-Peppas model & $\log Q_{t}=n \log t+\log k_{K-P}$ & $k_{K-P}$-the Korsmeyer-Peppas release constant $\left(\% \mathrm{~h}^{-1}\right)$ \\
\hline
\end{tabular}


Table 4. The parameters of the biocompounds' releases from the materials functionalized with triazine dendrons of generation $\mathrm{G} 2\left(\mathrm{Fe}_{3} \mathrm{O}_{4}-(\mathrm{CC}-\mathrm{p})_{2}\right.$ and $\left.\mathrm{Fe}_{3} \mathrm{O}_{4}-(\mathrm{CC}-\mathrm{DETA})_{2}\right)$ in $\mathrm{pH} 2.0$ and $\mathrm{pH} 7.4$, calculated for the first-order, the Higuchi, and the Korsmeyer-Peppas release models.

\begin{tabular}{|c|c|c|c|c|c|c|}
\hline & \multirow[b]{2}{*}{ Adsorbent } & \multicolumn{2}{|c|}{ Higuchi Model } & \multicolumn{3}{|c|}{ Korsemeyer-Peppas Model } \\
\hline & & $\begin{array}{c}k_{H} \\
\left(\% h^{-1 / 2}\right)\end{array}$ & $\mathbf{R}^{2}$ & $n$ & $\begin{array}{c}k_{K-P} \\
\left(\% h^{-1}\right)\end{array}$ & $\mathbf{R}^{2}$ \\
\hline \multicolumn{7}{|c|}{ Folic Acid } \\
\hline \multirow{2}{*}{ pH 2.0} & $\mathrm{Fe}_{3} \mathrm{O}_{4}-(\mathrm{CC}-\mathrm{p})_{2}$ & $2.7 \pm 0.5$ & 0.8561 & 0.06 & $62.7 \pm 0.6$ & 0.9676 \\
\hline & $\mathrm{Fe}_{3} \mathrm{O}_{4}-(\mathrm{CC}-\mathrm{DETA})_{2}$ & $2.4 \pm 0.4$ & 0.8435 & 0.05 & $71.4 \pm 0.5$ & 0.9717 \\
\hline \multirow{2}{*}{ pH 7.4} & $\mathrm{Fe}_{3} \mathrm{O}_{4}-(\mathrm{CC}-\mathrm{p})_{2}$ & $3.5 \pm 1.3$ & 0.5944 & 0.14 & $37.1 \pm 2.7$ & 0.7633 \\
\hline & $\mathrm{Fe}_{3} \mathrm{O}_{4}-(\mathrm{CC}-\mathrm{DETA})_{2}$ & $4.4 \pm 1.5$ & 0.6341 & 0.15 & $41.0 \pm 2.9$ & 0.7994 \\
\hline \multicolumn{7}{|c|}{ 18 $\beta-$ Glycyrrhetinic Acid } \\
\hline \multirow{2}{*}{ pH 2.0} & $\mathrm{Fe}_{3} \mathrm{O}_{4}-(\mathrm{CC}-\mathrm{p})_{2}$ & $4.1 \pm 1.2$ & 0.7087 & 0.10 & $55.6 \pm 1.8$ & 0.8967 \\
\hline & $\mathrm{Fe}_{3} \mathrm{O}_{4}-(\mathrm{CC}-\mathrm{DETA})_{2}$ & $3.0 \pm 1.2$ & 0.5353 & 0.07 & $67.0 \pm 2.7$ & 0.7295 \\
\hline \multirow{2}{*}{ pH 7.4} & $\mathrm{Fe}_{3} \mathrm{O}_{4}-(\mathrm{CC}-\mathrm{p})_{2}$ & $6.2 \pm 1.1$ & 0.8603 & 0.27 & $23.3 \pm 1.7$ & 0.9273 \\
\hline & $\mathrm{Fe}_{3} \mathrm{O}_{4}-(\mathrm{CC}-\mathrm{DETA})_{2}$ & $5.8 \pm 1.1$ & 0.8388 & 0.22 & $28.5 \pm 1.8$ & 0.9192 \\
\hline \multicolumn{7}{|c|}{ Vancomycin } \\
\hline \multirow{2}{*}{ pH 2.0} & $\mathrm{Fe}_{3} \mathrm{O}_{4}-(\mathrm{CC}-\mathrm{p})_{2}$ & $3.8 \pm 0.9$ & 0.7603 & 0.08 & $70.0 \pm 1.4$ & 0.9302 \\
\hline & $\mathrm{Fe}_{3} \mathrm{O}_{4}-(\mathrm{CC}-\mathrm{DETA})_{2}$ & $1.7 \pm 0.3$ & 0.8205 & 0.03 & $86.0 \pm 0.5$ & 0.9581 \\
\hline \multirow{2}{*}{ pH 7.4} & $\mathrm{Fe}_{3} \mathrm{O}_{4}-(\mathrm{CC}-\mathrm{p})_{2}$ & $4.6 \pm 1.2$ & 0.7395 & 0.13 & $47.5 \pm 2.0$ & 0.8922 \\
\hline & $\mathrm{Fe}_{3} \mathrm{O}_{4}-(\mathrm{CC}-\mathrm{DETA})_{2}$ & $2.7 \pm 0.8$ & 0.6832 & 0.07 & $60.8 \pm 1.5$ & 0.8664 \\
\hline
\end{tabular}

\section{Materials and Methods}

\subsection{Chemicals}

All the reagents used for the synthesis of triazine-dendrons, i.e., (3-Aminopropyl)trimethoxysilane (97\%), cyanuric chloride (cc) (99\%), piperazine (p) (99\%), diethylenetriamine (DETA) (99\%), and diisopropylethylamine ( $\geq 99 \%)$, and the chosen analytes: vancomycin hydrochloride hydrate, $18 \beta$-glycyrrhetinic acid (97\%), and folic acid ( $\geq 97 \%)$ were purchased from Sigma-Aldrich (Saint Louis, MO, USA). All the solvents and chemicals were of purity grade p.a. and were purchased from Stanlab (Lublin, Poland) (Hydrochloric acid conc., Sodium hydroxide, and Toluene), POCH (Gliwice, Poland) (Disodium phosphate dihydrate, Sodium phosphate monohydrate, and Potassium chloride), Eurochem BGD (Tarnów, Poland) (Sodium chloride, Tetrahydrofuran, and Dichloromethane), and Merck (Darmstadt, Germany) (Acetonitrile).

\subsection{Instruments}

The synthesized $\mathrm{Fe}_{3} \mathrm{O}_{4}$-based materials functionalized with triazine-based dendrons were characterized with transmission FT-IR spectroscopy using the Bruker IFS 66v/S (Bremen, Germany) spectroscope. The measurement conditions were as follows: wavelength range of $400-4000 \mathrm{~cm}^{-1}$; resolution of $2 \mathrm{~cm}^{-1}$; suspension of $1.5 \mathrm{mg}$ of the sample in $\mathrm{KBr}$ pellet. The materials were also characterized with nitrogen adsorption/desorption isotherms (Brauner-Emmet-Teller; BET) using the Quantachrome Autosorb iQ (Boynton Beach, USA) analyzer. The adsorption conditions were as follows: sample outgassing for $12 \mathrm{~h}$ at $100{ }^{\circ} \mathrm{C}$ before the analysis; the temperature-controlled analyses were performed at $77.35 \mathrm{~K}$; the time of analyses varied between 12.01 and $18.49 \mathrm{~h}$; the measurements were handled in the range of relative pressure $\mathrm{p} / \mathrm{p}_{0}$ between 0.0 and 1.0 . The raw data were further analyzed in order to calculate porosity parameters of the analyzed materials using BET and Barrett-Joyner-Halenda $(\mathrm{BJH})$ methods, applied in the range of $\mathrm{p} / \mathrm{p}_{0}$ between 0.05 to 0.3 and 0.1 to 1.0 , respectively.

The drugs' adsorption progress and their release to the adsorbing media were monitored with UV-Vis measurements using the Agilent 8453 spectrophotometer (Santa Clara, USA). The liquid samples were placed in a poly(methyl methacrylate) (PMMA) cuvette of an optical path length of $10 \mathrm{~mm}$. The spectra recorded in the wavelength range between 200 and $1000 \mathrm{~nm}$, with a resolution of $1 \mathrm{~nm}$, were conducted in triplicate to avoid any 
absorbance disturbances. The FAPA-MS spectra of the material-drug complexes were recorded using the Bruker amaZon SL ion trap (Bremen, Germany) spectrometer equipped with an L-FAPA ambient plasma source supplied by ERTEC (Wroclaw, Poland) [37]. External helium plasma as an ion source was generated by the gas flowing through a quartz tube at a rate of $1 \mathrm{~L} \mathrm{~min}^{-1}$, which gets discharged at the end of the tube by the open-circuit voltage of $20 \mathrm{kV}$, allowing the self-ignition of the gas. In order to analyze samples using such ionization mode, the samples were on mini-crucibles located approximately $5 \mathrm{~cm}$ below the plasma stream, which might have been heated up to $350{ }^{\circ} \mathrm{C}$. The vertical distance between the FAPA ionization source and the MS ions inlet was approximately $10 \mathrm{~cm}$. The mass spectrometer worked in a so-called 'enhanced resolution mode', affording the detection of $\mathrm{m} / \mathrm{z}$ in the range of 50 to 2200 with a scanning rate of $8100 \mathrm{~m} / \mathrm{z}$ per second. The spectrometer used helium as the cone gas at its flow rate of $50 \mathrm{~L} \mathrm{~h}^{-1}$.

\subsection{Synthesis of Magnetite Nanoparticles Functionalized with Triazine-Based Dendrons}

\subsubsection{Synthesis of Amino-Functionalized Magnetic Particles}

The synthesis of magnetite nanoparticles encapsulated with silica matrix was performed according to the previously described procedure [38]. The obtained magnetically susceptible support was further functionalized with (3-aminopropyl)-tri- methoxysilane (APTMS) in order to introduce free terminal amine groups on the surface. Therefore, a solution of APTMS $(392.8 \mu \mathrm{L} ; 2.25 \mathrm{mmol})$ in $50 \mathrm{~mL}$ of toluene was added dropwise into a suspension of $3 \mathrm{~g}$ of $\mathrm{Fe}_{3} \mathrm{O}_{4}-\mathrm{SiO}_{2}$ in $100 \mathrm{~mL}$ of toluene heated to a temperature of $50{ }^{\circ} \mathrm{C}$ with continuous stirring in an ultrasound bath. The sonification at a temperature of $50^{\circ} \mathrm{C}$ was maintained for $5 \mathrm{~h}$, and then the mixture was shaken at room temperature overnight. The resulting solid of $\mathrm{Fe}_{3} \mathrm{O}_{4}-\mathrm{NH}_{2}$ was magnetically separated, washed with toluene $(2 \times 50 \mathrm{~mL})$ and DCM $(2 \times 50 \mathrm{~mL})$, and dried under vacuum in a desiccator at room temperature.

\subsubsection{Quantification of the Amino Groups Loading}

The amount of the amine groups anchored to the $\mathrm{Fe}_{3} \mathrm{O}_{4}-\mathrm{NH}_{2}$ surface was examined using the classic acid-base titration technique. Namely, a $20 \mathrm{mg}$ sample of the material was mixed with $20 \mathrm{~mL}$ of $0.01 \mathrm{M}$ aqueous solution of $\mathrm{HCl}$ at room temperature for $2 \mathrm{~h}$. Afterwards, the solid was separated using a magnet, and the solute containing an excess of acid was titrated with $0.005 \mathrm{M}$ aqueous solution of $\mathrm{NaOH}$, using phenolphthalein as an indicator. The procedure was performed three times, calculating a mean value of amine groups' loading.

\subsubsection{Synthesis of $\mathrm{Fe}_{3} \mathrm{O}_{4}-\mathrm{CC}$ Precursor}

In the next step, cyanuric chloride (CC) was immobilized on the surface of the magnetite-based material. Therefore, to a solution of a 2-fold excess of CC (494.6 mg; $2.68 \mathrm{mmol})$ and DIPEA $(467.2 \mu \mathrm{L} ; 2.68 \mathrm{mmol})$ in $150 \mathrm{~mL}$ of THF cooled to temperature $\sim 2{ }^{\circ} \mathrm{C}$ in an ice-water bath, $3 \mathrm{~g}$ of $\mathrm{Fe}_{3} \mathrm{O}_{4}-\mathrm{NH}_{2}$ was added in several portions under continuous mechanical stirring, not to let the temperature rise. After the material's addition, the mixture was stirred for $2 \mathrm{~h}$ at lowered temperature and then separated using a magnet. The solid was washed with THF $(2 \times 50 \mathrm{~mL})$ and DCM $(2 \times 50 \mathrm{~mL})$ and dried under vacuum at room temperature, yielding $\mathrm{Fe}_{3} \mathrm{O}_{4}-\mathrm{CC}$ in dark brown.

\subsubsection{Synthesis of Triazine-Dendrons Containing Piperazine}

A solution of 1.5 -fold excess of piperazine $(173.3 \mathrm{mg} ; 2.01 \mathrm{mmol})$ and DIPEA $(350.4 \mu \mathrm{L}$; $2.01 \mathrm{mmol}$ ) in $100 \mathrm{~mL}$ of $\mathrm{ACN}$ was purged $\mathrm{N}_{2}$, and then $1.5 \mathrm{~g}$ of $\mathrm{Fe}_{3} \mathrm{O}_{4}-\mathrm{CC}$ was added to the solution in a few portions under mechanical stirring at room temperature. The stirring was maintained for $16 \mathrm{~h}$, and then the mixture was refluxed for another $24 \mathrm{~h}$. Afterwards, the mixture was cooled, the solid was separated with a magnet, washed with ACN $(2 \times 30 \mathrm{~mL})$ and DCM $(2 \times 30 \mathrm{~mL})$, and dried in the desiccator at room temperature, yielding $\mathrm{Fe}_{3} \mathrm{O}_{4}{ }^{-}$ $\mathrm{CC}-\mathrm{p}$ in dark brown. Half of the obtained material $(0.75 \mathrm{~g})$ was further reacted again 
with cyanuric chloride (185.4 mg; $1.01 \mathrm{mmol})$ and piperazine $(173.3 \mathrm{mg} ; 2.01 \mathrm{mmol})$ in the presence of DIPEA, following the same synthetic procedure of the substitution of CC (described in Section 3.3.3) and the subsequent substitution of piperazine (described above), obtaining a dark brown solid of $\mathrm{Fe}_{3} \mathrm{O}_{4}-(\mathrm{CC}-\mathrm{p})_{2}$.

\subsubsection{Synthesis of Triazine-Dendrons Containing Diethylenetriamine (DETA)}

The adopted synthetic procedure for obtaining the dendrons containing cyanuric chloride and diethylenetriamine was similar to the one described in Section 3.3.4. Briefly, $1.5 \mathrm{~g}$ of $\mathrm{Fe}_{3} \mathrm{O}_{4}-\mathrm{CC}$ was added to an anhydrous solution of DETA $(217.1 \mu \mathrm{L} ; 2.01 \mathrm{mmol})$ and DIPEA $(350.4 \mu \mathrm{L} ; 2.01 \mathrm{mmol})$ in several portions and then mixed for $16 \mathrm{~h}$ at room temperature and for $24 \mathrm{~h}$ at reflux. Then, a half $(0.75 \mathrm{~g})$ of separated, washed, and dried $\mathrm{Fe}_{3} \mathrm{O}_{4}$-CC-DETA was added in a few portions to a cooled solution of CC (370.7 mg; $2.01 \mathrm{mmol})$ and DIPEA $(350.4 \mu \mathrm{L} ; 2.01 \mathrm{mmol})$ at a temperature $2{ }^{\circ} \mathrm{C}$ in $75 \mathrm{~mL}$ of THF. The mixing was maintained for $2 \mathrm{~h}$ at a lowered temperature. Afterwards, the separated, washed, and dried material was added to a solution of DETA $(434.3 \mu \mathrm{L} ; 4.02 \mathrm{mmol})$ and DIPEA (700.8 $\mu \mathrm{L} ; 4.02 \mathrm{mmol})$ in $75 \mathrm{~mL}$ of ACN previously purged with $\mathrm{N}_{2}$. The mechanical stirring was continued for $16 \mathrm{~h}$, and then the mixture was refluxed for $24 \mathrm{~h}$, obtaining $\mathrm{Fe}_{3} \mathrm{O}_{4}-(\mathrm{CC}-\mathrm{DETA})_{2}$.

\subsubsection{Quantification of the Dendrons Loading on the Materials' Surface}

The procedure for the quantification of the amount of the amine groups introduced on the hybrid materials' surface was the same as described in paragraph Section 3.3.2. The classic acid-base titration using $0.01 \mathrm{M}$ aqueous solution of $\mathrm{HCl}$ and $0.005 \mathrm{M}$ aqueous solution of $\mathrm{NaOH}$ was performed for all the materials containing surface triazine-based dendrons.

\subsection{Sorption Experiments}

\subsubsection{Adsorption of the Chosen Acidic Bioactive Compounds}

The isothermal adsorption studies involved the incubation of $10 \mathrm{mg}$ samples of $\mathrm{Fe}_{3} \mathrm{O}_{4}-\mathrm{CC}-\mathrm{p}, \mathrm{Fe}_{3} \mathrm{O}_{4}-(\mathrm{CC}-\mathrm{p})_{2}, \mathrm{Fe}_{3} \mathrm{O}_{4}-\mathrm{CC}-\mathrm{DETA}$, or $\mathrm{Fe}_{3} \mathrm{O}_{4}-(\mathrm{CC}-\mathrm{DETA})_{2}$ in a series of $10 \mathrm{~mL}$ biocompounds' solutions at concentrations of $0.01,0.025,0.05,0.1,0.5$, and $1 \mathrm{mM}$. The solvents were chosen according to the biocompounds used, i.e., distilled water for vancomycin, phosphate buffer $\mathrm{pH} 8.0$ for folic acid, and distilled water:ethanol (1:3) mixture for $18 \beta$-glycyrrhetinic acid. The mixtures of the materials and the solutions were shaken for $24 \mathrm{~h}$ at room temperature. Afterwards, the materials were separated from the samples by centrifugation prior to separation using a magnet. The solutes were further analyzed using UV-Vis spectrophotometric assays, detecting the absorbance values at $\lambda$ of 358,254 , and $280 \mathrm{~nm}$ for folic acid, vancomycin, and $18 \beta$-glycyrrhetinic acid, respectively. On the basis of the calculated concentration of the biocompounds remaining in the solution after the adsorption experiments, the amount of the drugs bound to the materials $\left(q_{e q}\right)$ was calculated using Equation (1):

$$
q_{e q}=\frac{\left(c_{0}-c_{e q}\right) \cdot V \cdot M}{m}
$$

where $c_{0}$ and $c_{e q}$ are the initial and equilibrium concentration of the biocompounds, respectively, $(\mathrm{mM}) ; m$ is the sample mass $(\mathrm{mg}) ; V$ is the volume of the solution $(\mathrm{mL}) ; M$ is the molar mass of the analytes $\left(\mathrm{g} \mathrm{mol}^{-1}\right)$. Moreover, the solids of $\mathrm{Fe}_{3} \mathrm{O}_{4}-(\mathrm{CC}-\mathrm{p})_{2}$ and $\mathrm{Fe}_{3} \mathrm{O}_{4}-(\mathrm{CC}-\mathrm{DETA})_{2}$ incubated with the most concentrated solutions of the biomolecules were also further dried under vacuum and subjected to FAPA-MS analysis.

\subsubsection{Biocompounds Release Experiments}

Investigation of drug-delivery potential of the obtained materials was performed in two steps: (1) loading the drugs onto the surface of $\mathrm{Fe}_{3} \mathrm{O}_{4}-(\mathrm{CC}-\mathrm{p})_{2}$ and $\mathrm{Fe}_{3} \mathrm{O}_{4}-(\mathrm{CC}-$ DETA $)_{2}$; (2) incubation of material-drug complexes in phosphate-buffered saline (PBS) 
or hydrochloric acid/potassium chloride buffer $\mathrm{pH}$ 2.0. Therefore, $50 \mathrm{mg}$ samples of $\mathrm{Fe}_{3} \mathrm{O}_{4}-(\mathrm{CC}-\mathrm{p})_{2}$ and $\mathrm{Fe}_{3} \mathrm{O}_{4}-(\mathrm{CC}-\mathrm{DETA})_{2}$ were shaken with $20 \mathrm{~mL}$ of $1 \mathrm{mM}$ solutions of vancomycin, $18 \beta$-glycyrrhetinic acid, or folic acid for $24 \mathrm{~h}$ at room temperature. Afterwards, the materials were centrifuged and separated using a magnet and then dried in the desiccator at room temperature. The amount of the drugs complexed on the materials' surface was determined using UV-Vis measurements, as described in Section 3.4.1. Then, samples of the material-drug complexes (ca. $15 \mathrm{mg}$ ) were incubated in $5 \mathrm{~mL}$ of pre-prepared PBS or $\mathrm{HCl} / \mathrm{KCl}$ buffer at room temperature. The buffer aliquots were replaced with a fresh buffer after $0.5,1,2,4,8,24$, and $48 \mathrm{~h}$ of incubation. The solutes were subjected to UV-Vis analysis in order to quantify the cumulative drug release $F_{t}$ and cumulative percentage of the drug released $Q_{t}$, according to Equations (2) and (3), respectively:

$$
\begin{aligned}
& F_{t}=\sum_{i=0}^{t} c_{t} \cdot V \cdot M \\
& Q_{t}=\frac{F_{t}}{m_{0}} \cdot 100 \%
\end{aligned}
$$

where $c_{t}$ is the concentration of the released drug $(\mathrm{M}) ; V$ is the volume of the releasing medium (mL); $M$ is the drug's molar mass $\left(\mathrm{g} \mathrm{mol}^{-1}\right) ; m_{0}$ is the mass of the drug in the studied material-drug complex (mg).

\section{Conclusions}

Recent studies have shown the synthetic approach for obtaining the triazine-based dendron-functionalized magnetite nanoparticles, which were characterized for adsorptive properties towards the chosen acidic bioactive molecules. The iterative nucleophilic substitution steps led to obtaining branched domains on the support's surface with a dendron-loading efficiency of $0.195,0.180,0.117$, and $0.069 \mathrm{mmol} \mathrm{g}^{-1}$ for $\mathrm{Fe}_{3} \mathrm{O}_{4}-\mathrm{CC}-\mathrm{p}$, $\mathrm{Fe}_{3} \mathrm{O}_{4}-(\mathrm{CC}-\mathrm{p})_{2}, \mathrm{Fe}_{3} \mathrm{O}_{4}-\mathrm{CC}-\mathrm{DETA}$, and $\mathrm{Fe}_{3} \mathrm{O}_{4}-(\mathrm{CC}-\mathrm{DETA})_{2}$, respectively. The materials showed satisfactory adsorption properties towards folic acid, $18 \beta$-glycyrrhetinic acid, and vancomycin, depending on either the dendron's structure or the adsorbate structure. Additionally, the materials containing second-generation dendrons exhibited promising in vitro drug-transport efficiency, described by a drug release percentage between $56.4 \%$ and $95.2 \%$ after incubation in paraphysiological buffered solutions. Therefore, such materials may be utilized as direct drug-delivery platforms, which can be easily directed by an external magnetic field. This physical property of the materials allows for their exact introduction to organs or tissues. Moreover, since the materials showed efficient binding of folic acida structure that biodirects to over-expressed folic acid receptors of mutated cells-such complex might be useful as an easily recognized agent for hyperthermia treatment. The mentioned bioapplications of the proposed materials, however, must be proved by proper assays and experiments, which are the nearest plans of our studies.

Supplementary Materials: The following are available online at https://www.mdpi.com/article/ $10.3390 /$ ijms222111353/s1.

Author Contributions: Conceptualization, M.P. and G.S.; methodology, M.P.; software, M.P.; validation, M.P. and G.S.; formal analysis, M.P.; investigation, M.P.; resources, M.P. and G.S.; data curation, M.P.; writing—original draft preparation, M.P.; writing—review and editing, G.S.; visualization, M.P.; supervision, G.S.; project administration, M.P. and G.S.; funding acquisition, M.P. and G.S. All authors have read and agreed to the published version of the manuscript.

Funding: This research was funded by the European Union through the European Social Fund under the Operational Program Knowledge Education Development, grant number POWR.03.02.00-00I026/16.

Institutional Review Board Statement: Not applicable.

Informed Consent Statement: Not applicable. 
Data Availability Statement: The data presented in this study are available on request from the corresponding author.

Conflicts of Interest: The authors declare no conflict of interest.

\section{References}

1. Ramachandran, R.; Jung, D.; Bernier, N.A.; Logan, J.K.; Waddington, M.A.; Spokoyny, A.M. Sonochemical synthesis of small boron oxide nanoparticles. Inorg. Chem. 2018, 57, 8037-8041. [CrossRef]

2. Oleshkevich, E.; Teixidor, F.; Rosell, A.; Vinas, C. Merging icosahedral boron clusters and magnetic nanoparticles: Aiming toward multifunctional nanohybrid materials. Inorg. Chem. 2018, 57, 462-470. [CrossRef] [PubMed]

3. Xiao, D.; Lu, T.; Zeng, R.; Bi, Y. Preparation and highlighted applications of magnetic microparticles and nanoparticles: A review on recent advances. Microchim. Acta 2016, 183, 2655-2675. [CrossRef]

4. Ghazanfari, M.R.; Kashefi, M.; Shams, S.F.; Jaafari, M.R. Perspective of $\mathrm{Fe}_{3} \mathrm{O}_{4}$ Nanoparticles Role in Biomedical Applications. Biochem. Res. Int. 2016, 2016, 7840161. [CrossRef] [PubMed]

5. Mieloch, A.A.; Kręcisz, M.; Rybka, J.D.; Strugała, A.; Krupiński, M.; Urbanowicz, A.; Kozak, M.; Skalski, B.; Figlerowicz, M.; Giersig, M. The influence of ligand charge and length on the assembly of Brome mosaic virus derived virus-like particles with magnetic core. AIP Adv. 2018, 8, 35005-35013. [CrossRef]

6. Su, C. Environmental implications and applications of engineered nanoscale magnetite and its hybrid nanocomposites: A review of recent literature. J. Hazard. Mater. 2017, 332, 48-84. [CrossRef]

7. Guć, M.; Schroeder, G. Application of Molecularly Imprinted Polymers (MIP) and Magnetic Molecularly Imprinted Polymers (mag-MIP) to Selective Analysis of Quercetin in Flowing Atmospheric-Pressure Afterglow Mass Spectrometry (FAPA-MS) and in Electrospray Ionization Mass Spectrometry (ESI-MS). Molecules 2019, 24, 2364.

8. Mintzer, M.A.; Grinstaff, M.W. Biomedical applications of dendrimers: A tutorial. Chem. Soc. Rev. 2011, 40, 173-190. [CrossRef]

9. Ambekar, R.S.; Choudhary, M.; Kandasubramanian, B. Recent advances in dendrimer-based nanoplatform for cancer treatment: A review. Eur. Polym. J. 2020, 126, 109546. [CrossRef]

10. Viltres, H.; Lopez, Y.C.; Leyva, C.; Gupta, N.K.; Naranjo, A.G.; Acevedo-Pena, P.; Sanchez-Diaz, A.; Bae, J.; Kim, K.S. Polyamidoamine dendrimer-based materials for environmental applications: A review. J. Mol. Liq. 2021, 334, 116017. [CrossRef]

11. Zheng, W.; Simanek, E.E. Dendrimers Based on Melamine. Divergent and Orthogonal, Convergent Syntheses of a G3 Dendrimer. Org. Lett. 2000, 2, 843-845. [CrossRef] [PubMed]

12. Patel, R.M.; Patel, H.N.; Gajjar, D.; Patel, P.M. Enhanced Solubility of Non-Steroidal Anti-Inflammatory Drugs by Hydroxyl Terminated S-Triazine Based Dendrimers. Asian J. Pharm. Clin. Res. 2014, 7, 156-161.

13. Gajjar, D.; Patel, R.M.; Patel, V.A.; Patel, P.M. Novel hydroxyl terminated dendrimers as potential drug carriers: Sustained release, hemolysis and cytotoxicity study. Int. J. Appl. Pharm. 2015, 7, 5-9.

14. Vembu, S.; Pazhamalai, S.; Gopalakrishnan, M. Potential antibacterial activity of triazine dendrimer: Synthesis and controllable drug release properties. Bioorg. Med. Chem. 2015, 23, 4561-4566. [CrossRef] [PubMed]

15. Vembu, S.; Pazhamalai, S.; Gopalakrishnan, M. Synthesis, spectral characterization, and effective antifungal evaluation of 1H-tetrazole containing 1,3,5-triazine dendrimers. Med. Chem. Res. 2016, 25, 1916-1924. [CrossRef]

16. Lim, J.; Lo, S.T.; Hill, S.; Pavan, G.M.; Sun, X.; Simanek, E.E. Antitumor Activity and Molecular Dynamics Simulations of Paclitaxel-Laden Triazine Dendrimers. Mol. Pharm. 2012, 9, 404-412. [CrossRef]

17. Merkel, O.M.; Mintzer, M.A.; Librizzi, D.; Samsonova, O.; Dicke, T.; Sproat, B.; Garn, H.; Barth, P.J.; Simanek, E.E.; Kissel, T. Triazine Dendrimers as Nonviral Vectors for in Vitro and in Vivo RNAi: The Effects of Peripheral Groups and Core Structure on Biological Activity. Mol. Pharm. 2010, 7, 969-983. [CrossRef]

18. Golikand, A.N.; Didehban, K.; Irannejad, L. Synthesis and Characterization of Triazine-Based Dendrimers and Their Application in Metal Ion Adsorption. J. Appl. Polym. Sci. 2012, 123, 1245-1251. [CrossRef]

19. Gajjar, D.; Patel, R.M.; Patel, H.N.; Patel, P.M. Removal of heavy metal ions from water by Hydroxyl terminated Triazine-based Dendrimer. Desalin. Water Treat. 2015, 55, 1209-1219. [CrossRef]

20. Wu, Q.; You, R.; Lv, Q.; Xu, Y.; You, W.; Yu, Y. Efficient simultaneous removal of $\mathrm{Cu}(\mathrm{II})$ and $\mathrm{Cr}_{2} \mathrm{O}_{7}{ }^{2-}$ from aqueous solution by a renewable amphoteric functionalized mesoporous silica. Chem. Eng. J. 2015, 281, 491-501. [CrossRef]

21. Anbia, M.; Haqshenas, M. Adsorption studies of $\mathrm{Pb}(\mathrm{II})$ and $\mathrm{Cu}$ (II) ions on mesoporous carbon nitride functionalized with melamine-based dendrimer amine. Int. J. Environ. Sci. Technol. 2015, 12, 2649-2664. [CrossRef]

22. Arshadi, M.; Faraji, A.R.; Amiri, M.J. Modification of aluminum-silicate nanoparticles by melamine-based dendrimer L-cysteine methyl esters for adsorptive characteristic of $\mathrm{Hg}$ (II) ions from the synthetic and Persian Gulf water. Chem. Eng. J. 2015, 266, 345-355. [CrossRef]

23. Beyki, M.H.; Feizi, F.; Shemirani, F. Melamine-based dendronized magnetic polymer in the adsorption of $\mathrm{Pb}(\mathrm{II})$ and preconcentration of rhodamine B. React. Funt. Polym. 2016, 103, 81-91. [CrossRef]

24. Anbia, M.; Khoshobooei, S. Functionalized magnetic MCM-48 nanoporous silica by cyanuric chloride for removal of chlorophenol and bromophenol from aqueous media. J. Nanostruct. Chem. 2015, 5, 139-146. [CrossRef]

25. Fardjahromi, M.A.; Moghadam, M.; Tangestaninejad, S.; Mirkhani, V.; Mohammadpoor-Baltork, I. Manganese(III) Salophen Supported on Silica Containing Triazine Dendrimer: An Efficient Catalyst for Epoxidation of Alkenes with Sodium Periodate. RSC Adv. 2016, 6, 20128-20134. [CrossRef] 
26. Asadi, B.; Mohammadpoor-Baltork, I.; Tangestaninejad, S.; Moghadam, M.; Mirkhani, V.; Nasr-Esfahani, M. Synthesis and characterization of $\mathrm{Bi}(\mathrm{III})$ immobilized on triazine dendrimer-stabilized magnetic nanoparticles: A reusable catalyst for synthesis of aminonaphthoquinones and bisaminonaphthoquinones. New J. Chem. 2016, 40, 6171-6184. [CrossRef]

27. Pan, S.; Yao, S.; Osako, T.; Uozumi, Y. Controlled Aerobic Oxidation of Primary Benzylic Alcohols to Aldehydes Catalyzed by Polymer-Supported Triazine-Based Dendrimer-Copper Composites. Synlett 2018, 29, 1152-1156. [CrossRef]

28. Eskandari, A.; Jafarpour, M.; Rezaeifard, A.; Salimi, M. A dendritic $\mathrm{TiO}_{2}-\mathrm{Co}$ (II) nanocomposite based on the melamine catalyzed one-pot aerobic photocatalytic synthesis of benzimidazoles. New J. Chem. 2018, 42, 6449-6456. [CrossRef]

29. Pan, S.; Yao, S.; Osako, T.; Uozumi, Y. Batch and Continuous-Flow Huisgen 1,3-Dipolar Cycloadditions with an Amphiphilic Resin-Supported Triazine-Based Polyethyleneamine Dendrimer Copper Catalyst. ACS Sustain. Chem. Eng. 2017, 5, 10722-10734. [CrossRef]

30. Young, K.L.; Xu, C.; Xie, J.; Sun, S. Conjugating Methotrexate to magnetite $\left(\mathrm{Fe}_{3} \mathrm{O}_{4}\right)$ nanoparticles via trichloro-s-triazine. J. Mater. Chem. 2009, 19, 6400-6409. [CrossRef]

31. Isfahani, A.L.; Moghadam, M.; Mohammadi, S.; Royvaran, M.; Moshtael-Arani, N.; Rezaei, S.; Tangestaninejad, S.; Mirkhani, V.; Mohammadpoor-Baltork, I. An Elegant pH-Responsive Nanovehicle for Drug Delivery Based on Triazine Dendrimer Modified Magnetic Nanoparticles. Langmuir 2017, 34, 8503-8515. [CrossRef] [PubMed]

32. Fu, R.; Jin, X.; Liang, J.; Zheng, W.; Zhuang, J.; Yang, W. Preparation of nearly monodispersed $\mathrm{Fe}_{3} \mathrm{O}_{4} / \mathrm{SiO}_{2}$ composite particles from aggregates of $\mathrm{Fe}_{3} \mathrm{O}_{4}$ nanoparticles. J. Mater. Chem. 2011, 21, 15352. [CrossRef]

33. Moreno, K.X.; Simanek, E.E. Identification of diamine linkers with differing reactivity and their application in the synthesis of melamine dendrimers. Tetrahedron Lett. 2008, 49, 1152-1154. [CrossRef]

34. Orta, M.D.M.; Martin, J.; Medina-Carrasco, S.; Santos, J.L.; Aparicio, I.; Alonso, E. Adsorption of propranolol onto montmorillonite: Kinetic, isotherm and pH studies. Appl. Clay Sci. 2019, 173, 107-114. [CrossRef]

35. Kim, Y.S.; Kim, J.H. Isotherm, kinetic and thermodynamic studies on the adsorption of paclitaxel onto Sylopute. J. Chem. Thermodyn. 2019, 130, 104-113. [CrossRef]

36. Wua, I.Y.; Balaa, S.; Skalko-Basneta, N.; Pio di Cagno, M. Interpreting non-linear drug diffusion data: Utilizing Korsmeyer-Peppas model to study drug release from liposomes. Eur. J. Pharm. Sci. 2019, 138, 105026. [CrossRef]

37. Guć, M.; Reszke, E.; Cegłowski, M.; Schroeder, G. Construction of Plasma Ion Sources to be Applied in Analysis of Small Organic Compounds Using Mass Spectrometry. Plasma Chem. Plasma Process. 2020, 40, 235-260. [CrossRef]

38. Pawlaczyk, M.; Pasieczna-Patkowska, S.; Schroeder, G. Photoacoustic Spectroscopy of Surface-Functionalized $\mathrm{Fe}_{3} \mathrm{O}_{4}-\mathrm{SiO}_{2}$ Nanoparticles. Appl. Spectr. 2020, 74, 712-719. [CrossRef] [PubMed] 